\title{
Opinion
}

\section{What Is the Optimal Sodium Concentration in the Dialysate?}

\author{
Salvador López-Gil and Magdalena Madero *
}

check for

updates

Citation: López-Gil, S.; Madero, M. What Is the Optimal Sodium Concentration in the

Dialysate? Kidney Dial. 2022, 2, 4-5. https://doi.org/10.3390/

kidneydial2010002

Academic Editors: Manfred Hecking, Peter Kotanko and Jochen

G. Raimann

Received: 18 November 2021

Accepted: 28 December 2021

Published: 31 December 2021

Publisher's Note: MDPI stays neutral with regard to jurisdictional claims in published maps and institutional affiliations.

Copyright: (C) 2021 by the authors. Licensee MDPI, Basel, Switzerland. This article is an open access article distributed under the terms and conditions of the Creative Commons Attribution (CC BY) license (https:// creativecommons.org/licenses/by/ $4.0 /)$.
Departamento de Nefrología, Instituto Nacional de Cardiologia Ignacio Chavez, Mexico City 14080, Mexico; salvadorlgil@gmail.com

* Correspondence: madero.magdalena@gmail.com

\begin{abstract}
Based on our experience in our hemodiafiltration unit we would recommend a personalized isonatremic dialysate bath. We currently prescribe $137 \mathrm{meq}$ (isonatremic) or delta dialysate $\mathrm{Na} / \mathrm{serum}$ $\mathrm{Na}$ less than 2 meq. In addition to the sodium prescribed in the dialysate, for the majority of our patients we do not restrict dietary sodium or water intake. The average sodium intake is $2775 \mathrm{mg}$ per day and blood pressure is maintained without hypertensive medications. We acknowledge that part of the success for achieving dry weight may not be attributable only to the dialysate sodium but is likely the result of a combination of multiple factors such as convection therapy, cooling of dialysate, close monitoring of volume status during sessions with relative blood volume, presence of a nephrologist during all sessions and assessing volume status regularly with lung ultrasound and bioimpedance. In our experience, exercising during hemodialysis has additionally been associated with better hemodynamic status and less intradialytic hypotension. Moreover, we acknowledge there is little evidence to support a gradient dialysate to serum sodium of less than 2 meq and that our approach may not be optimal.
\end{abstract}

Keywords: sodium; dialysate; dry weight

"You are being put in charge as the Medical Director of a newly-built dialysis clinic in your country. In consideration of available resources and reimbursement policies - how would you prescribe the dialysate sodium concentration for your patients? What would your approach be and why?"

Based on our experience in our hemodiafiltration unit we would recommend a personalized isonatremic dialysate bath. We currently prescribe $137 \mathrm{meq}$ (isonatremic) or delta dialysate $\mathrm{Na}$ /serum $\mathrm{Na}$ less than 2 meq. Our hemodialysis machines have online clearance measurement using conductivity where urea clearance is established through serum sodium. For the majority of our patients a fixed $137 \mathrm{meq} \mathrm{Na}$ is prescribed, with less than $10 \%$ of our population using the delta dialysate $\mathrm{Na} /$ serum $\mathrm{Na}$ of less than 2 meq in those subjects that have serum sodium higher than the average for our population (140 meq/L). None of our patients use DNa less than 137.

In addition to the sodium prescribed in the dialysate, for the majority of our patients we do not restrict dietary sodium or water intake. The average sodium intake is $2775 \mathrm{mg}$ per day and blood pressure is maintained without hypertensive medications. For instance, during 2020 the average pre- and post-dialysis blood pressure (BP) was 140/76 ( $\pm 30 / 16.5)$ $\mathrm{mmHg}$ and $131 / 73( \pm 33.9 / 15.3) \mathrm{mmHg}$, respectively, with only $5 \%$ patients requiring blood pressure medications. The mean interdialytic weight gain is $1.9 \pm 0.9 \mathrm{~kg}$ and we prescribe a 3 to 3.5 hour, thrice weekly session in most patients, perform monthly bioimpedance to assess volume status, and the use of ultrasound has become a daily practice in our center. We acknowledge that part of the success for achieving dry weight may not be attributable only to the dialysate sodium but is likely a combination of multiple factors such as convection therapy, cooling of dialysate, close monitoring of volume status during the sessions with relative blood volume, presence of a nephrologist during all sessions and assessing volume status regularly with lung ultrasound and bioimpedance. We have 
implemented point of care ultrasound (POCUS) in our unit and measure inferior vena cava (IVC) diameter, portal vein pulsatility fraction (PVPF), jugular vein at rest (YVR) and hepatic vein flow (HVF) at five points: pre-dialysis, three times during dialysis and post-dialysis. In addition, our patients exercise throughout the session using a stationary bicycle. In our experience exercising during hemodialysis has additionally been associated with better hemodynamic status and less intradialytic hypotension.

Moreover, we acknowledge there is little evidence to support a gradient dialysate to serum sodium of less than 2 meq and that our approach may not be optimal. Ideally, we should be measuring the difference between the prescribed sodium and the dialysate sodium as it is detailed that the prescribed versus delivered sodium may be discrepant when standard measurement methods are used. For patients who do not reach dry weight, rather than incrementing the sodium in dialysate bath we would first increase the ultrafiltration volumes, even if this requires additional treatment time. This approach, although ideal, is limited by government reimbursement policies and is not feasible for the majority of our patients. Regardless, if this approach is not possible, we suggest avoiding hypernatremic dialysate as it increases interdialytic weight gain and blood pressure.

The only scenario where we prescribe higher dialysate sodium baths is in the setting of acute kidney injury and volume overload. We believe that providing a higher sodium in the dialysate could help hemodynamic stability where larger ultrafiltration volumes are required.

Author Contributions: Conceptualization, S.L.-G. and M.M.; methodology, M.M.; validation, M.M.; writing—original draft preparation, S.L.-G.; writing—review and editing, M.M.; visualization, M.M.; supervision, M.M. All authors have read and agreed to the published version of the manuscript.

Funding: This research received no external funding.

Institutional Review Board Statement: Not applicable.

Informed Consent Statement: Not applicable.

Data Availability Statement: Not applicable.

Conflicts of Interest: The authors declare no conflict of interest. 